Faculdade

de Ciências Econômicas UFRGS
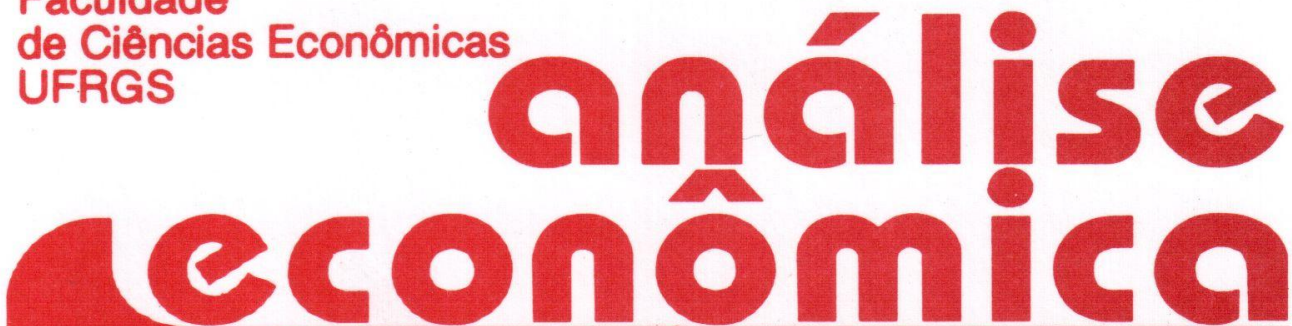

- globalização, Blocos REgIONAIS E O SETOR AGRÍ́COLA NO MERCOSUL Paulo D. Waquil

- globalização: ReALIdAde E UTOPIA

Gentil Corazza

- DO FOREIGN CURRENCY DEPOSITS DID THEY IMPROVE WELFARE?

Carlos A. Janada

- MACROECONOMIC INSTABILITY AND STRATEGIES OF TRANSNATIONAL CORPORATIONS IN BRAZIL

Reinaldo Gonçalves

- INFRASTRUCTURE, PUBLIC CAPITAL AND GROWTH IN THE BRAZILIAN ECONOMY

Stefano Florissi

+ EFEITOS DO PLANO REAL SOBRE O RIO GRANDE DO SUL Marcelo S. Portugal

- REgIONALIZAÇÃo dA MATRIZ dE INSUMO-PRODUTO E O IMPACTO DO AUMENTO DA PRODUÇÃO DE GRÃOS NO RS E NO BRASIL

Nali de Jesus de Souza

- IMPORTACõES DE LEITE E A PECUÁRIÁ LEITEIRA NO BRASIL Silvinha P. Vasconcelos

- ANPEC: CURSO PREPARATÓRIO

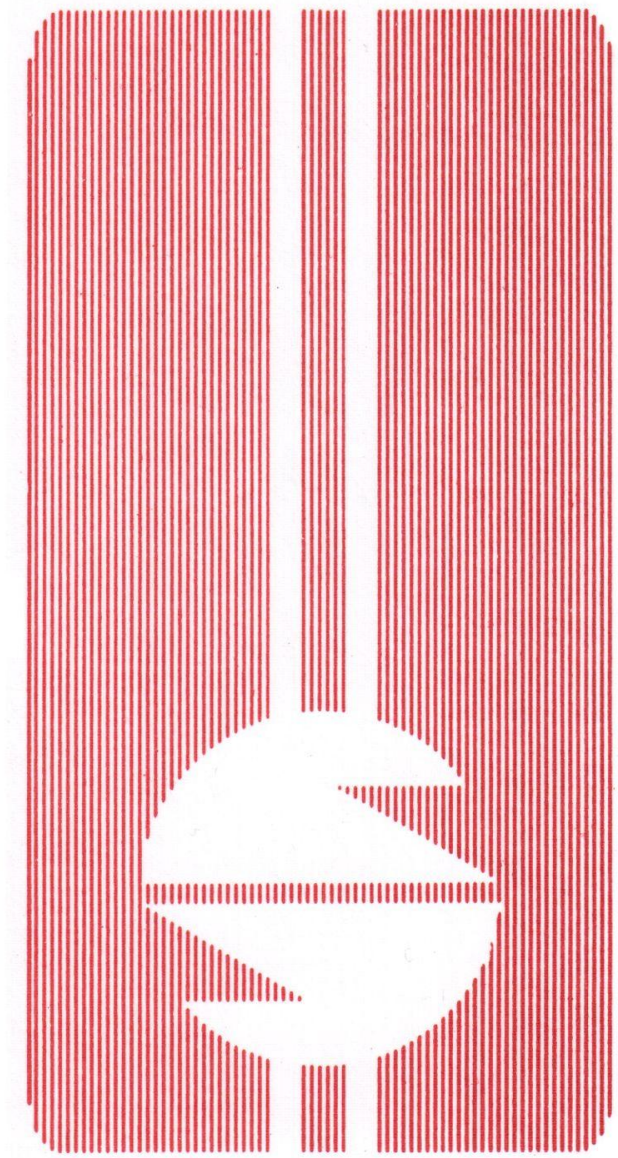


UNIVERSIDADE FEDERAL DO RIO GRANDE DO SUL

Reitor. Prof ${ }^{a}$. Wrana Maria Panizzi

FACULDADE DE CIÊNCIAS ECONÔMICAS

Diretor. Prof'. Otília Beatriz Kroeff Carrion

CENTRO DE ESTUDOS E PEQUISAS ECONÔMICAS

Diretor: Prof. Paulo Alexandre Spohr

DEPARTAMENTO DE CIÊNCIAS ECONÔMICAS

Chefe: Prof. Gentil Corazza

CURSO DE PÓS-GRADUAÇÃO EM ECONOMIA

Coordenador. Prof. Marcelo Savino Portugal

CURSO DE PÓS-GRADUAÇÃO EM ECONOMIA RURAL.

Coordenador. Prof. Carlos Guilherme A. Mielitz Netto

CONSELHO EDITORIAL: Achyles Barcelos da Costa, Aray Miguel Feldens, Carlos Augusto Crusius, Carlos Guilherme A. Mielitz Netto, Eugênio Lagemann, Fernando Ferrari Filho, Gentil Corazza, Marcelo Savino Portugal, Nali de Jesus de Souza, Otília Beatriz K. Carrion, Paulo Alexandre Spohr, Paulo Dabdab Waquil, Pedro Cezar Dutra Fonseca, Roberto Camps Moraes, Valter José Stülp, David Garlow (Wharton Econometrics Forecasts Association, E.U.A.), Edgar Augusto Lanzer (UFSC), Eleutério F. S. Prado (USP), Fernando de Holanda Barbosa (FGV/RJ), Gustavo Franco (PUC/RJ), João Rogério Sanson (UFSC), Joaquim Pinto de Andrade (UnB), Juan H. Moldau (USP), Werner Baer (Univ. de Illinois, E.U.A.).

COMISSÃO EDITORIAL: Fernando Ferrari Filho, Gentil Corazza, Paulo Dabdab Waquil, Marcelo Savino Portugal, Roberto Camps Moraes.

EDITOR: Nali de Jesus de Souza

SECRETARIA: Cláudia Porto Silveira, Jeferson Luis Bittencourt. Revisão de textos: Vanete Ricachescki.

FUNDADOR: Prof. Antônio Carlos Santos Rosa

Os materiais publicados na revista Análise Econômica são da exclusiva responsabilidade dos autores. É permitida a reprodução total ou parcial dos trabalhos, desde que seja citada a fonte. Aceita-se permuta com revistas congêneres. Aceitam-se, também, livros para divulgação, elaboração de resenhas e recensões. Toda correspondência, material para publicação (vide normas na terceira capa), assinaturas e permutas devem ser dirigidos ao seguinte destinatário:

PROF. NALI DE JESUS DE SOUZA

Revista Análise Econômica

Av. João Pessoa, 52

CEP 90040-000 PORTO ALEGRE - RS, BRASIL

Telefones: (051) 316-3348 e 316-3440

Fax: (051) 225-1067 


\section{EFEITOS DO PLANO REAL SOBRE \\ O RIO GRANDE DO SUL: AS EXPORTAÇÕES, \\ O NIVEL DE ATIVIDADE E AS FINANÇAS PÚBLICAS GAÚCHAS NOS DOIS PRIMEIROS ANOS DO REAL"}

Marcelo S. Portugal"

SINOPSE
o objetivo central deste artigo é o de analisar os impactos da política econômica
implementada nos dois primeiros anos do Plano Real sobre a economia do Estado do Rio
Grande do Sul. Neste artigo, vamos nos concentrar nos efeitos do Plano Real sobre três
aspectos básicos da economia gaúcha: nivel de atividade, exportações e finanças públicas. O
esforço de estabilização de preços que foi, em grande medida, baseado na valorização real da
taxa de câmbio e na queda dos preços agricolas, penalizou severamente o Rio Grande do Sul
que é, sabidamente, um Estado de grande produção agrícola e volume de exportações. Por
outro lado, a estabilização da inflação foi também responsável por uma deterioração das
finanças públicas estaduais em função do elevado peso da folha salarial no orçamento do
Estado.

\section{INTRODUÇÃO}

Não resta dúvida que, de forma geral, a estabilização de preços é bem vinda, tanto para a economia gaúcha como para a economia brasileira como um todo. As altas taxas de inflação viabilizavam um grande volume de ganhos inflacionários que beneficiavam apenas ao Governo e ao setor financeiro. A estabilização de preços, por um lado, promoveu uma significativa redistribuição de renda para os setores mais pobres da população, exatamente aqueles que não conseguiam se proteger da aceleração inflacionária e, por outro lado, gerou também um ganho de produtividade para a economia como um todo, na medida em que não apenas eliminou os custos reais da inflação, ${ }^{1}$ mas também permitiu

"Este texto foi elaborado para apresentação na audiência pública da Comissão de Finanças $e$ Tributação da Câmara dos Deputados em 8/8/1996, sobre o tema "O Brasil Visto do Rio Grande do Sul: Cornentários Sobre a Politica Econômica Atual".

** Professor do Curso de Pós-Graduação em Economia da UFRGS e pesquisador do CNPq. Gostaria de agradecer a colaboração dos bolsistas Suzana M. B. Coccaro (FAPERGS) e Vinícius Carrasco (CNPq).

Para uma taxa de inflação de $45 \%$ ao mês, Moraes (1995) estima que os custos reais anuais da inflação sejam de cerca de $8 \%$ do PIB.

\begin{tabular}{|c|c|c|c|}
\hline $\begin{array}{c}\text { Cód. AEA } \\
946\end{array}$ & $\begin{array}{c}\text { Palavras-chave: } \\
\text { economia gaúcha; Plano Real; economia regional. }\end{array}$ \\
\hline ANÁLISE ECONÔMICA & ANO 15 & Março de 1997 & p. 81-109 \\
\hline
\end{tabular}


uma redução do grau de incerteza na tomada de decisão dos agentes econômicos.

Contudo alguns equívocos e exageros na condução da política econômica tiveram efeitos profundamente negativos sobre o Rio Grande do Sul. Sendo um Estado com grande produção agrícola e vocação exportadora, o Rio Grande do Sul foi particularmente prejudicado pelo processo de valorização cambial, ocorrido na primeira fase do Plano Real, e pela, às vezes ausente mas sempre instável, política agrícola do governo. Além destes fatores específicos que atingiram mais fortemente o Rio Grande do Sul, o Estado sofreu também com outros problemas de âmbito mais geral, que atingiram todos os estados brasileiros, tais como a crise nas finanças públicas estaduais e a forte desaceleração econômica gerada pela politica crediticia crescentemente restritiva, implementada a partir do final de 1994.

\section{O PLANO REAL}

Mesmo depois do fracasso do Plano Cruzado, a idéia básica de que qualquer plano de estabilização de preços tinha, necessariamente, de incluir um congelamento geral de preços cristalizou-se na mente da maior parte dos economistas brasileiros. Seguiram-se ao Cruzado o Plano Bresser (junho de 1987), o Plano Verão (janeiro de 1989), o Plano Collor I (março de 1990) e o Plano Color II (janeiro de 1991), que também lançaram mão do artifício do congelamento geral de preços. Como pode ser visto pela Figura 1, em cada um destes planos, o congelamento foi efetivo para reduzir a inflação por apenas alguns meses. No entanto, até junho de 1994, a única alternativa oferecida publicamente ao congelamento total de preços era a criação de um pacto voluntário de salvação nacional que disciplinasse os aumentos de preços e salários. Em uma sociedade politicamente fragmentada e diferenciada como a brasileira, este tipo de proposta nunca foi levada à frente.

O Plano Real, ${ }^{2}$ iniciado em março de $1994 \mathrm{com}$ a introdução da Unidade Real de Valor (URV) ${ }^{3}$ e consolidado em julho do mesmo ano com a entrada em circulação do real, representou o abandono definitivo da estratégia de congelamento geral de preços que havia sido iniciada pelo Plano Cruzado.

\footnotetext{
2 Uma análise detalhada da politica econômica no período do Plano Real (1994/96) pode ser encontrada em Portugal (1996).

${ }^{3}$ Na verdade, o início do Plano Real pode ser datado em dezembro de 1993, a partir da criação do Fundo Social de Emergência (FSE), que "deveria" ter fornecido o equilibrio fiscal necessário ao fim da inflação.
} 
Figura 1

Taxas de inflação (IGP-DI) no Brasil, 1973-1996

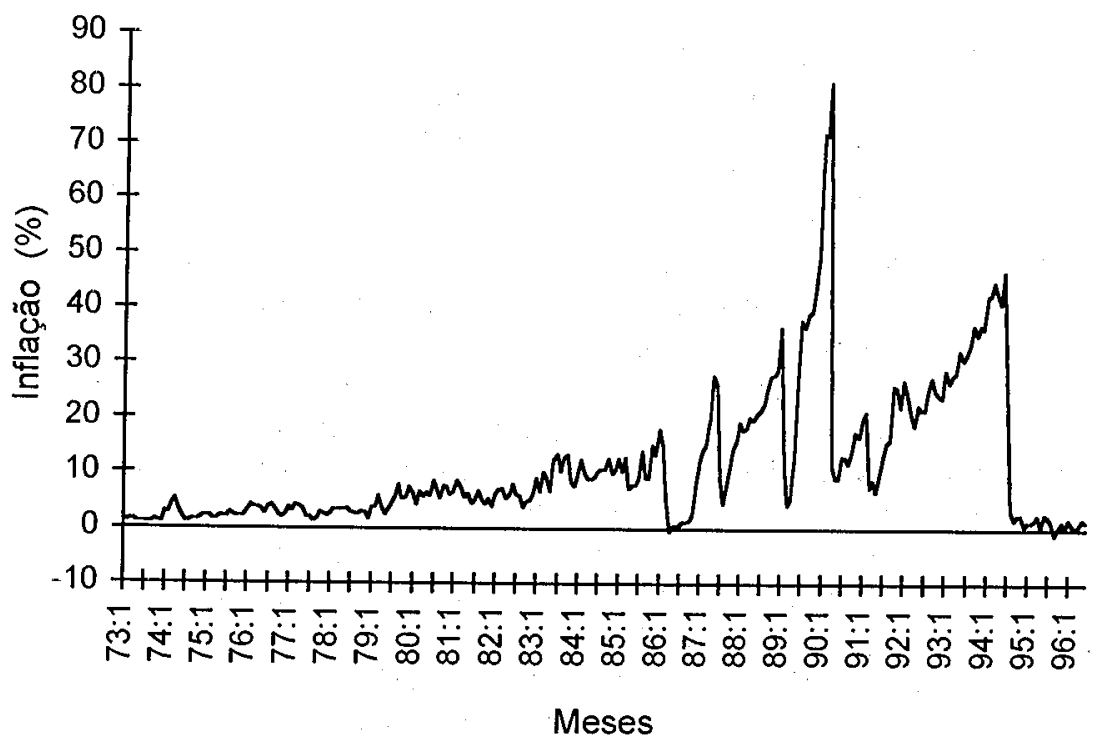

Fonte: Conjuntura Econômica.

Na verdade, o Plano Real representou uma retomada da Proposta Larida que havia sido preterida em fevereiro de $1986 \mathrm{em}$ favor do Plano Cruzado. Os elementos básicos do Plano Real já estavam presentes na Proposta Larida. A URV fez o papel originalmente destinado em 1986 à ORTN, vale dizer, foi utilizada para garantir um certo equilibrio dos preços relativos da economia, o qual muitas vezes fica desestabilizado pela alta inflação, de tal forma que a introdução do real fosse feita sem pressões para recomposição de preços: Outra semelhança fundamental entre o Plano Real e a Proposta Larida é a utilização da âncora cambial como forma de dar credibilidade à nova moeda. $\mathrm{Na}$ escolha entre a âncora monetária e a âncora cambial, a Proposta Larida destacava que "teoricamente, fixar a taxa de câmbio é uma alternativa superior a limitar o crescimento monetário". ${ }^{4}$ Embora reconhecendo a superioridade da

${ }^{4}$ Arida e Lara Resende (1986), p. 29. 
âncora cambial, a proposta Larida reconhecia também a dificuldade de sua aplicação no Brasil de 1986, pois àquela época inexistia o fluxo de capitais externos necessários. Neste sentido, a mudança no cenário internacional, no que diz respeito ao fluxo de capitais para a América Latina entre os anos oitenta e noventa, e a política de acumulação de reservas feita durante a gestão do ministro Marcílio Marques Moreira foram fundamentais para garantir a solidez da âncora cambial e, conseqüentemente, do Plano Real.

As principais diferenças em relação à Proposta Larida foram a explicitação da importância do ajuste das contas do setor público e da abertura da economia como elementos-chave para o sucesso a longo prazo do plano de estabilização. No diagnóstico da inflação que norteou o Plano Real, fica claro que a criação da URV e a reforma monetária que introduziu o real são elementos que visavam a eliminar apenas a inflação inercial. Neste sentido, como preparação para o Plano Real foi implementada, através do Fundo Social de Emergência (FSE), uma desvinculação parcial das receitas fiscais de tal forma a reter nas mãos da União eventuais ganhos com o aumento da arrecadação tributária. Como no Brasil as receitas fiscais são indexadas à inflação e as despesas orçamentárias são fixas em termos nominais, a taxa de inflação encobre a real situação fiscal da economia. Desta forma, a obtenção de um equilibrio orçamentário com uma taxa de inflação elevada pode levar a um grande déficit público nominal, quando a inflação se reduz rapidamente. A Figura 2 serve para ilustrar esta situação. Note que as despesas nominais são fixas em relação à inflação, mas as receitas fiscais nominais são positivamente relacionadas com a inflação. Para uma inflação de, por exemplo, $30 \%$ temos equilíbrio fiscal em função do crescimento nominal da receita, mas este equilibrio é apenas aparente, pois oculta um substancial déficit nominal para uma taxa de inflação baixa.

Já o processo de abertura da economia brasileira à concorrência externa, iniciado a partir dos anos noventa durante o Governo Collor, foi particularmente importante no que diz respeito à contenção das pressões inflacionárias na fase inicial do Plano Real, quando ocorreu um grande crescimento do consumo. A Proposta Larida, elaborada numa época onde o isolamento econômico era uma quase unanimidade, não fazia qualquer menção à importância da utilização da concorrência externa como um fator de aumento de produtividade e contenção de preços para a economia brasileira.

Infelizmente, apesar do reconhecimento explícito da necessidade de um equilibrio fiscal permanente e do grande aumento da arrecadação tributária ocorrido desde o inicio do Plano Real, que elevou a carga tributária bruta para $30,5 \%$ do PIB em 1995, o governo não tem sido capaz de eliminar o descontrole das contas públicas. Os grandes responsáveis por este descontrole são a imobilidade do Governo Federal em promover uma ampla desvinculação 
dos gastos públicos, que permitisse o corte de despesas no volume necessário e nas áreas relevantes, e a lentidão em implantar uma reforma administrativa, gerencial e patrimonial do estado brasileiro. O FSE, hoje rebatizado de Fundo de Estabilização Fiscal (FEF), que foi fundamental para garantir o equilibrio orçamentário precário obtido em 1994, está longe de promover a desvinculação de gastos requerida pela estabilização de preços. Neste sentido, o Plano Real só vai se completar quando as causas básicas da inflação, que são o descontrole das contas públicas e a conseqüente expansão monetária, forem definitivamente eliminadas. Até então, nós teremos que utilizar artifícios de curto prazo, tais como a sobrevalorização do câmbio e a politica de juros altos, que propiciam um elevado nivel de reservas internacionais e mantêm a economia relativamente desaquecida, para manter a inflação sob controle.

Figura 2

Déficit público nominal e inflaçẵo

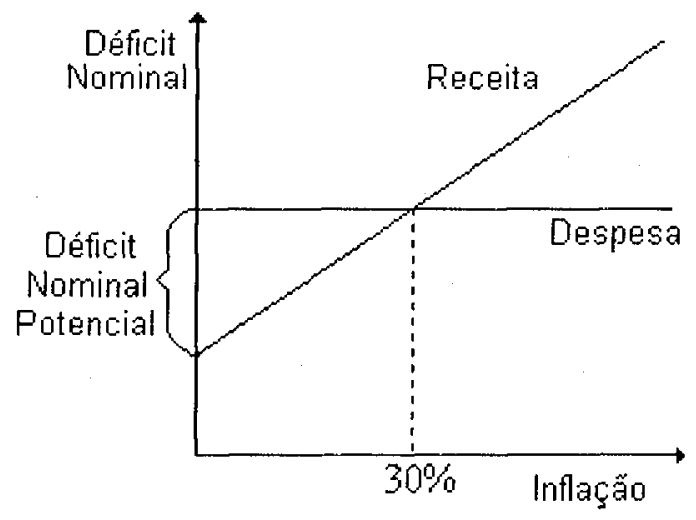

A teoria econômica nos ensina que a "politica monetária sozinha é apenas capaz de adiar a inflação", pois "sem o auxilio da política fiscal o combate à inflação hoje, através de uma política monetária restritiva vai, eventualmente, levar a uma maior inflação no futuro". Neste sentido, o déficit público e o crescimento explosivo da divida pública a partir de dezembro de 1994 são as principais causas de preocupação quanto ao futuro a médio e longo prazo do Plano Real. A dívida pública vai ter de ser paga no futuro a partir da arrecadação tributária ou da expansão monetária. $\mathrm{Na}$ medida em que o

${ }^{5}$ Sargent e Wallace (1986). 
crescimento exagerado desta divida comece a gerar expectativas de que será inevitável uma expansão monetária futura, o Plano Real estará em perigo.

A experiência internacional já demonstrou que são quatro os principais problemas que podem contribuir para o insucesso de um plano de estabilização de preços. Em primeiro lugar, temos a ameaça representada pelo aumento substancial do consumo, que ocorre em função da redução do imposto inflacionário e da redistribuição de renda decorrentes da redução drástica da inflação. A expansão exagerada do consumo neste primeiro momento da estabilização de preços pode levar a uma pressão de demanda pela elevação de preços. Em segundo lugar, existe a possibilidade de uma grande crise bancária, que pode ocorrer não apenas pela eliminação dos ganhos inflacionários, que são auferidos pelos bancos em regimes de inflação alta, mas também por um aumento da inadimplência, em função dos efeitos recessivos que, em geral, ocorrem após um período de crescimento econômico inicial. Em terceiro lugar, temos a possibilidade de uma crise externa que produza um déficit acentuado do balanço de pagamentos $e$, conseqüentemente, uma desvalorização real substancial da taxa de câmbio, reanimando, assim, a inflação e a indexação. Por último, existe a possibilidade de que, uma vez eliminado o componente inercial da inflação, não seja concretizado o ajuste fiscal permanente que é, em última instância, a causa básica da inflação.

No caso brasileiro, com a superação da crise do México, a redução nos níveis de consumo e a instituição do Programa de Estímulo à Reestruturação e ao Fortalecimento do Sistema Financeiro Nacional (PROER), já conseguimos evitar três destes problemas. Falta agora atingir o equilíbrio fiscal permanente, pois o descontrole das contas públicas continua a ser a grande ameaça ao Plano Real.

\section{A POLÍTICA CAMBIAL E AS EXPORTAÇÕES GAÚCHAS}

A importância do estabelecimento de uma âncora nominal, como parte central de qualquer processo de estabilização de preços em economias de inflação alta e crônica, é algo relativamente consensual na literatura. ${ }^{6}$ Nas experiências bem-sucedidas de estabilização presentes, sejam elas "heterodoxas", como no caso de Israel, ou "ortodoxas", como no caso do Chile, ou passadas, como no caso da Alemanha em 1923, a fixação da taxa de câmbio nominal desempenhou um papel fundamental no sentido de garantir a credibilidade da moeda nacional. Outro exemplo recente da importância da manutenção de uma taxa de câmbio fixa para garantir a credibilidade do Banco Central e, por conseqüência, da moeda por ele emitida, é fornecido pelas

\footnotetext{
${ }^{6}$ Ver, por exemplo, Lopes (1991)
} 
experiências argentina e italiana. No caso da Itália, como destacado por Giavazzi e Pagano (1988), a fixação de uma paridade nominal entre a lira e o marco alemão, estabelecida a partir da entrada da Itália no Sistema Monetário Europeu (SME), foi fundamental para garantir credibilidade da politica antiinflacionária adotada.

Este ganho de credibilidade do governo é fruto da disciplina monetária e fiscal que deve ser obedecida para a manutenção da paridade cambial. Note-se que a fixação da taxa nominal de câmbio, como parte da política de estabilização, só faz sentido se acompanhada da austeridade monetária e fiscal necessárias, de forma a impedir uma excessiva sobrevalorização da moeda nacional e, conseqüentemente, a acumulação de déficits comerciais crescentes. Outra alternativa para evitar a sobrevalorização cambial é a redução dos custos domésticos de produção que viabilize um ganho de produtividade suficiente para manter a competitividade das exportações. Neste particular, o Brasil ainda tem muito o que fazer no sentido de reduzir aquilo que já ficou conhecido como - "custo Brasil", tais como os custos portuários e de transporte, os impostos incidentes sobre as exportações, tais como o Confins e o ICMS na exportação de produtos não manufaturados, entre outros. No entanto, enquanto não houver este ganho de credibilidade da moeda nacional fundamentado no equilíbrio fiscal permanente, vai ser necessário manter um fluxo constante de entrada de capitais internacionais e um elevado volume de reservas como forma de sustentar a estabilidade cambial.

O cerne do problema cambial brasileiro está na primeira fase da política cambial brasileira, entre julho a outubro de 1994, quando o governo permitiu que houvesse uma valorização nominal do real em relação ao dólar. Neste período, a âncora cambial brasileira foi ainda mais firme que a da Argentina ou a dos países do SME, pois, em função do superávit comercial existente no início do Plano Real e da forte entrada de capital estrangeiro de curto prazo, a taxa de câmbio nominal valorizou-se seguidamente, chegando a ser cotada a $0,827 \mathrm{R} \$$ /US $\$$ em meados de outubro de 1994. Está neste período a origem da maior parte da sobrevalorização cambial brasileira. Tomando-se a variação diária da taxa de câmbio nominal ponta-a-ponta entre o início de julho a meados de outubro, a taxa de câmbio nominal valorizou-se em $17,30 \%$.

Em outubro, inicia-se uma segunda fase da politica cambial brasileira, que perduraria até março de 1995, quando o governo passa a dar prioridade à sustentação da taxa de câmbio nominal como forma de impedir o aprofundamento do processo de sobrevalorização da taxa de câmbio real. A principal medida neste sentido foi o estabelecimento informal pelo Banco Central de um sistema de bandas para a taxa de câmbio nominal, visando mantê-la entre os limites de 0,85 R\$/US\$ e 0,83 R\$/US\$. Ainda em outubro, 
para auxiliar a manutenção do limite inferior da banda cambial informal, foram tomadas diversas medidas para estimular a demanda por dólares e desestimular a oferta de dólares. Entre elas destacam-se a redução para o prazo de fechamento dos Adiantamentos de Contratos de Câmbio (ACCs), a redução tarifária, especialmente para bens de consumo durável, o aumento dos impostos incidentes sobre a entrada de capital e relaxamento das restrições sobre pagamentos ao exterior. Algumas fontes do governo chegaram mesmo a colocar a obtenção de um déficit na balança comercial, que ajudaria o combate à inflação e a sustentação da taxa de câmbio, como um objetivo de política econômica para o ano de 1995.

Figura 3

Taxa de câmbio nominal diária

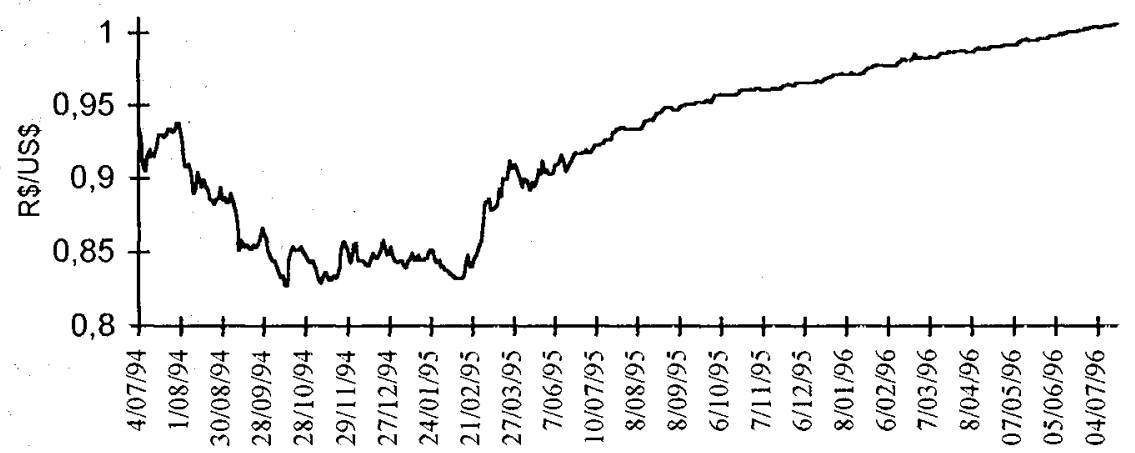

Dias

Fonte: Gazeta Mercantil.

A terceira fase da política cambial brasileira, que iniciou-se em março de 1995 , tem suas origens na crise mexicana de dezembro de 1994. Com a redução do fluxo de capitais de curto prazo para a América Latina, gerada pela crise mexicana, e os déficits na balança comercial, que entre novembro de 1995 e março de 1996 já acumulavam US\$ 3,71 bilhões, o governo brasileiro viu-se forçado a alterar novamente a politica cambial. Na verdade, a politica de geração de déficits comerciais com o objetivo de aumentar a oferta doméstica e combater a inflação foi relativizada em favor da busca de um certo equilíbrio da balança comercial. Foi estabelecida, agora formalmente, uma banda de variação, entre $0,88 \mathrm{R} \$ /$ US\$ e $0,93 \mathrm{R} \$ / \mathrm{US} \$$, para a taxa de câmbio nominal. $\mathrm{Na}$ 
prática, contudo, iniciou-se um processo de desvalorização lento mas continuado da taxa de câmbio nominal, balizado pelo estabelecimento de minibandas informais que eram corrigidas periodicamente pelo Banco Central sem um cronograma predeterminado. Para permitir esta desvalorização contínua do real frente ao dólar, as bandas passaram a ser modificadas sempre que a taxa de câmbio se aproximava do limite superior da banda. Assim, em junho de 1995 as bandas formais foram reajustadas para $0,91 \mathrm{R} \$ / \mathrm{US} \$$ e 0,99 R\$/US\$ e, em janeiro de 1996, para 0,97 R\$/US\$ e 1,06 R\$/US\$. Em um certo sentido, pode-se dizer que esta mudança representou uma volta ao sistema de minidesvalorizações cambiais que foi usado no Brasil entre as décadas de sessenta e oitenta. As medidas de contenção da oferta e incentivo à demanda de dólares adotadas em outubro foram integralmente revogadas, a tarifa de importação de automóveis e diversos produtos eletro-eletrônicos foi elevada para $70 \%$. Graças ao auxílio financeiro dado pelos Estados Unidos ao México, os impactos da crise mexicana sobre o restante da América Latina puderam ser minimizados e, já no segundo semestre de 1995, foram restabelecidos os fluxos de capital de curto prazo para o Brasil.

Esta politica cambial acabou por provocar uma defasagem real da taxa de câmbio entre $10 \%$ e $20 \%$, dependendo dos indices de preço utilizados como deflatores e do período escolhido como base de comparação.

Tabela 1. Desempenho das exportações (em bilhões de US\$)

\begin{tabular}{l|r|r|r|r|r|r}
\hline & Mundo & Var. \% & \multicolumn{1}{c}{ Brasil } & Var. \% & R. G. S. & Var. \% \\
\hline 1993 & 3824,4 & - & 38,597 & - & 5,212 & - \\
1994 & 4364,0 & 14,12 & 43,545 & 12,82 & 5,028 & $-3,53$ \\
1995 & 5239,4 & 20,06 & 46,506 & 6,80 & 5,181 & 3,04 \\
\hline
\end{tabular}

Fonte: IFS/IMF (june 1996) e DPPC/SECEX.

A Tabela 1 deixa claro como a política cambial prejudicou sensivelmente as exportações brasileiras e do Rio Grande do Sul, que apresentaram um desempenho medíocre nos anos de 1994 e 1995. Enquanto as exportações mundiais cresceram $37 \%$ neste biênio, influenciadas positivamente pelo forte crescimento da economia mundial neste periodo, as exportações brasileira cresceram em apenas $20,51 \%$ e as exportações gaúchas em $-0,59 \%$. O desempenho das exportações brasileiras e gaúchas só não foi pior graças a fatores exógenos à politica econômica do governo, tais como o aumento de preços de vários commodities e o crescimento da economia mundial. 
Tabela 2. Principais produtos de exportação do Rio Grande do Sul (em milhões de US\$)

\begin{tabular}{l|r|r|r|r}
\hline Capítulos da NBM & \multicolumn{1}{|c|}{1993} & 1994 & 1995 & \multicolumn{1}{|c}{$\begin{array}{c}1996 \\
\text { (jan/jun) }\end{array}$} \\
\hline Calçados, polainas e artef. semelhantes & 1556,9 & 1286,6 & 1245,2 & 675,5 \\
Fumo (tabaco) e sucedâneos manufaturados & 605,2 & 628,0 & 677,2 & 478,9 \\
Residuos indústrias aliment.; alim. p/ animais & 532,7 & 467,1 & 480,5 & 278,5 \\
Caldeiras, maq., apar. e instr. mecânicos & 239,4 & 263,2 & 288,7 & 178,9 \\
Peles, exceto peleteria e couros & 204,6 & 182,5 & 198,2 & 113,5 \\
Gorduras, óleos e ceras, animais e vegetais & 190,9 & 296,6 & 342,3 & 110,2 \\
Carnes e miudezas comestiveis & 188,6 & 195,5 & 192,4 & 106,3 \\
Plásticos e suas obras & 185,5 & 194,4 & 182,0 & 89,1 \\
Veículos automóveis, tratores, etc. & 156,3 & 208,9 & 175,6 & 84,1 \\
Borracha e suas obras & 106,8 & 48,5 & 86,0 & 58,8 \\
Complexo Soja & 993,2 & 966,9 & 948,7 & 407,4 \\
\hline
\end{tabular}

Fonte: DPPC/SECEX.

No Rio Grande do Sul, o setor de calçados, que responde por cerca de $25 \%$ da pauta da exportações gaúchas, foi um dos mais afetados, apresentando uma queda de exportações de $20 \%$ no biênio. O complexo soja (farelo, óleo e soja triturada) e o fumo, que representam cerca de, respectivamente, $18 \%$ e $13 \%$ das exportações gaúchas, foram relativamente menos afetados em função de aumentos de preços no mercado internacional. Recentemente, as exportações gaúchas iniciaram um processo de reação fazendo com que as exportações acumuladas nos últimos doze meses aumentassem de US\$ 5,181 bilhões em dezembro de 1995 para US\$ 5,458 bilhões em maio de 1996, representando assim um incremento de 5,35\%. Este aumento das exportações está novamente ligado a fatores exógenos à política econômica brasileira para o setor, sendo explicado, principalmente, pelo extraordinário aumento nos preços da soja, trigo e milho no mercado internacional.

\section{A CRISE NO SETOR PRODUTIVO GAÚCHO}

A política creditícia crescentemente restritiva implementada pelo Governo Federal a partir do final de 1994 começou a mostrar seus efeitos recessivos sobre o desempenho da indústria brasileira a partir do início de 1995. A Figura 4, que apresenta o desempenho da produção física da indústria brasileira com ajuste sazonal para o periodo de janeiro de 1994 a maio de 1996, deixa clara a existência de três fases distintas desde o início do Plano Real. Depois de uma pequena queda de $2,84 \%$ entre janeiro e junho de 1994, a produção industrial cresceu aceleradamente no segundo semestre do ano apresentando um crescimento de $14,74 \%$. Inicia-se então, a partir de janeiro de 1995, uma 
segunda fase caracterizada por um movimento de queda acentuada da produção industrial que, até julho de 1995, recuou em 11,41\%. Neste sentido, podemos dizer que nesta segunda fase foi eliminado grande parte do ganho de produção que havia sido acumulado durante o segundo semestre de 1994. A partir do segundo semestre de 1995 ocorre uma estabilização da produção industrial em um nível ligeiramente acima daquele existente antes do Plano Real, como pode ser visto pela Figura 4, onde a linha horizontal indica o nivel de produção desazonalizado da indústria em junho de 1994.

Uma análise mais desagregada do desempenho da indústria mostra algumas diferenças de desempenho importantes entre os diversos gêneros da indústria. Na Tabela 3, apresentamos o nivel de produção antes do início do Plano Real, e os níveis de produção mais alto e mais baixo atingidos durante 0 Plano Real. Em primeiro lugar, cabe destacar que, em nenhum setor da indústria, a produção física em maio de 1996, o dado mais recente disponível, conseguiu restabelecer os níveis vigentes no mês de maior produção desde o início do Plano Real. Por outro lado, embora não se tenham ainda restabelecido estes niveis máximos de produção, é somente no caso do setor de Couros e Peles que o mês de maio de 1996 apresentou o pior indicador de produção desde o início do Plano Real. Para todos os demais setores, o nivel mínimo de produção gerado pela política recessiva/de controle de inflação do governo já foi superado. Para oito setores industriais, Materiais Elétricos e de Comunicação, Minerais Não-Metálicos, Papel e Papelão, Mobiliário, Farmacêutico, Perf. Sabões e Velas, Produtos de Matérias Plásticas e Bebidas, o nivel mais baixo de produção foi atingido ainda no primeiro mês de vigência do Plano Real, julho de 1994, evidenciando assim que estes setores foram relativamente menos atingidos pela retração na produção industrial, ocorrida a partir de janeiro de 1995. Os setores que apresentam o melhor desempenho em relação a junho de 1994 são: Produtos de Matérias Plásticas (35,66\%), Mobiliário $(33,22 \%)$, Perf. Sabões e Velas $(32,53 \%)$, Farmacêutico $(21,83 \%)$, Materiais Elétricos e de Comunicação (16,27\%), Produtos Alimentares $(14,54 \%)$, Minerais Não-Metálicos (12,43\%), e Bebidas (11,88\%). Aqueles com pior desempenho são: Couros e Peles $(-22,90 \%)$, Mecânica $(-12,82 \%)$ e Têxtil ($9,83 \%)$. Os setores que estão mais distantes do nível de produção máximo atingido durante o Plano Real são Mecânica, Têxtil, Vestuário e Calçados, respectivamente, $32,53 \%, 26,88 \%, 23,52 \%$ abaixo do máximo. Em resumo, o comportamento da indústria frente à política recessiva de controle de inflação do governo foi bastante diferenciado. 
Figura 4

Índice de produção física da indústria brasileira

(com ajuste sazonal)

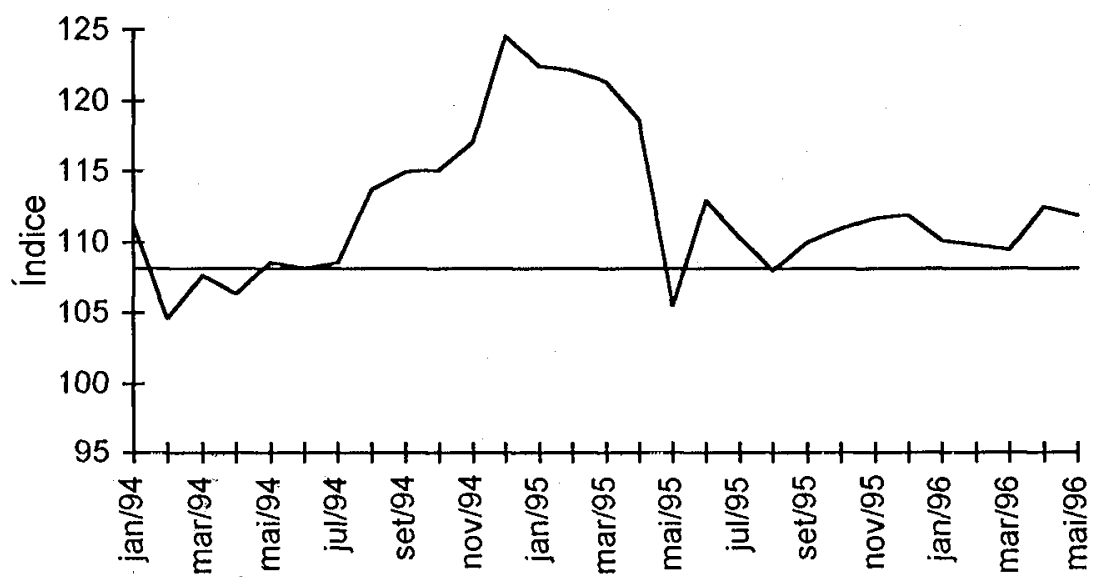

Fonte: IBGE/DPE/Departamento de Indủstria

No caso do Rio Grande do Sul, a análise da série da produção física da indústria do IBGE e do Índice de Desempenho Industrial (IDI) da Federação das Indústrias do Rio Grande do Sul (FIERGS), apresentados nas Tabelas A4 e A2 do anexo estatístico, revelam que a indústria gaúcha passou por fases semelhantes àquelas da indústria brasileira. O IDI é um indicador abrangente que mede o comportamento de cinco variáveis-chave para a indústria: compras e vendas da indústria, salário médio, utilização de capacidade instalada e horas trabalhadas na produção. É possivel visualizar pela Figura 5 que o IDI apresentou uma aceleração rápida após o Plano Real atingindo taxas de crescimento mensal, em relação ao mesmo mês do ano anterior, da ordem de $16 \%$ para meses de dezembro de 1994 a março de 1995. A partir de então o IDI indica uma rápida desaceleração da indústria gaúcha entre março e agosto de 1996, com taxas de crescimento negativas entre agosto de 1995 e março de 1996. A partir de abril deste ano o IDI volta a apresentar taxas de crescimento positivas, indicando assim o início de um possivel processo de retomada de crescimento da indústria gaúcha. 
Tabela 3. Índice de produção física com ajuste sazonal e taxas de variação selecionadas da indústria de transformação brasileira $(1991=100)$

\begin{tabular}{|c|c|c|c|c|c|c|c|}
\hline Gêneros Industriais & $\begin{array}{c}\text { Indice } \\
\text { em jun } \\
94 \\
\end{array}$ & $\begin{array}{l}\text { Índice no Pico } \\
\text { do Plano Real }\end{array}$ & $\begin{array}{l}\text { Indice no Vale } \\
\text { do Plano Real }\end{array}$ & \begin{tabular}{|c|} 
Indice \\
em mai \\
96 \\
\end{tabular} & \begin{tabular}{|c|} 
Var. \\
mai $96 /$ \\
jun 94 \\
\end{tabular} & $\begin{array}{c}\text { Var. mai } \\
96 / \\
\text { vale }\end{array}$ & \begin{tabular}{|l} 
ii Var. mai \\
$96 /$ \\
Pico \\
\end{tabular} \\
\hline Indústria Geral & 108,09 & 124,53 (dez-94) & $\begin{array}{c}105,55 \text { (maio- } \\
95 \text { ) }\end{array}$ & 111,85 & $3,48 \%$ & $5,97 \%$ & $-10,18 \%$ \\
\hline $\begin{array}{l}\text { Indústria de } \\
\text { Transformação } \\
\text { Minerais Não- }\end{array}$ & 108,03 & 125,49 (dez-94) & $\mid 107,61$ (ago-95) & 112,22 & $3,88 \%$ & $4,28 \%$ & $-10,57 \%$ \\
\hline & 96,83 & 112,03 (dez-94) & 90,77 (jul-94) & 108,87 & $12,43 \%$ & $19,94 \%$ & $-2,82 \%$ \\
\hline & 114,55 & & & & $\mid-2,64 \%$ & & $-16,31 \%$ \\
\hline Gótric & 121,25 & 156,69 (jan-95) & 98,86 (dez-95) & 105,71 & $|-12,82 \%|$ & $6,93 \%$ & $-32,53 \%$ \\
\hline & 114,51 & 141,36 & & 133,14 & $16,27 \%$ & $15,25 \%$ & $-5,81 \%$ \\
\hline & 124,29 & & & 55 & $5,84 \%$ & & $-20,78 \%$ \\
\hline & 97,50 & 116,0 & 93,6 & 102,16 & $4,78 \%$ & $9,14 \%$ & $-12,0 \%$ \\
\hline & 99,7 & \begin{tabular}{|c|}
132,87 (maio- \\
$96)$
\end{tabular} & & 132,87 & $33,22 \%$ & $41,30 \%$ & $0 \%$ \\
\hline & & 114,79 & & & $2 \%$ & $9 \%$ & $-8,55 \%$ \\
\hline & 11 & & & 117,88 & $6,59 \%$ & $21,58 \%$ & $-12,68 \%$ \\
\hline & & & & 78,45 & $-22,90 \%$ & $0 \%$ & $-23,18 \%$ \\
\hline & $113, \mathrm{C}$ & 122 & 70 & 111,81 & $-1,12 \%$ & & $-8,94 \%$ \\
\hline $\begin{array}{l}\text { êtica } \\
\text { aria, }\end{array}$ & & 121,62 (abr-95) & & 105,94 & $21,83 \%$ & & $-12,89 \%$ \\
\hline Sabões e Velas & 93,78 & $\begin{array}{c}124,29 \text { (maio- } \\
96 \text { ) }\end{array}$ & 85,38 (jul-94) & 124,29 & $32,53 \%$ & $45,57 \%$ & $0 \%$ \\
\hline $\begin{array}{l}\text { Prod. Mat. } \\
\text { Plásticas }\end{array}$ & 90,97 & 127,15 (dez-94) & $86,19($ jul-94) & 123,41 & $35,66 \%$ & $43,18 \%$ & $-2,94 \%$ \\
\hline $\begin{array}{l}\text { Têxtil } \\
\text { Vestuário, }\end{array}$ & 91,94 & $\mid 113,37$ (dez-94) & 77,09 (ago-95) & 82,90 & $-9,83 \%$ & 7,54 & $-26,88 \%$ \\
\hline $\begin{array}{l}\text { Calçados } \\
\text { e Art. de Tecidos } \\
\text { Produtos }\end{array}$ & 96,10 & $\mid 114,16$ (dez-94) $\mid$ & $\mid 83,39$ (mar-96) & 87,31 & $-9,15 \%$ & 4,70 & $-23,52 \%$ \\
\hline & 101,96 & & 102 & 116,78 & & 14,06 & \\
\hline umo & 11350 & $\mid \begin{array}{c}135,14 \text { (mar-95) } \\
116,39 \text { (jan-96) }\end{array}$ & $\mid \begin{array}{l}85,95 \text { (jul-94) } \\
78,89 \text { (fev-95) }\end{array}$ & $\begin{array}{l}107,52 \\
112,63\end{array}$ & $\begin{array}{r}11,88 \% \\
-0,77 \%\end{array}$ & $\begin{array}{l}25,10 \\
42,77\end{array}$ & $\begin{array}{l}-20,44 \% \\
-3,23 \%\end{array}$ \\
\hline & & & & & & & \\
\hline
\end{tabular}

Fonte: IBGE/DPE/Departamento de Indústria 
Figura 5

Indice de desempenho industrial do Rio Grande do Sul (variação em relação ao mesmo mês do ano anterior)

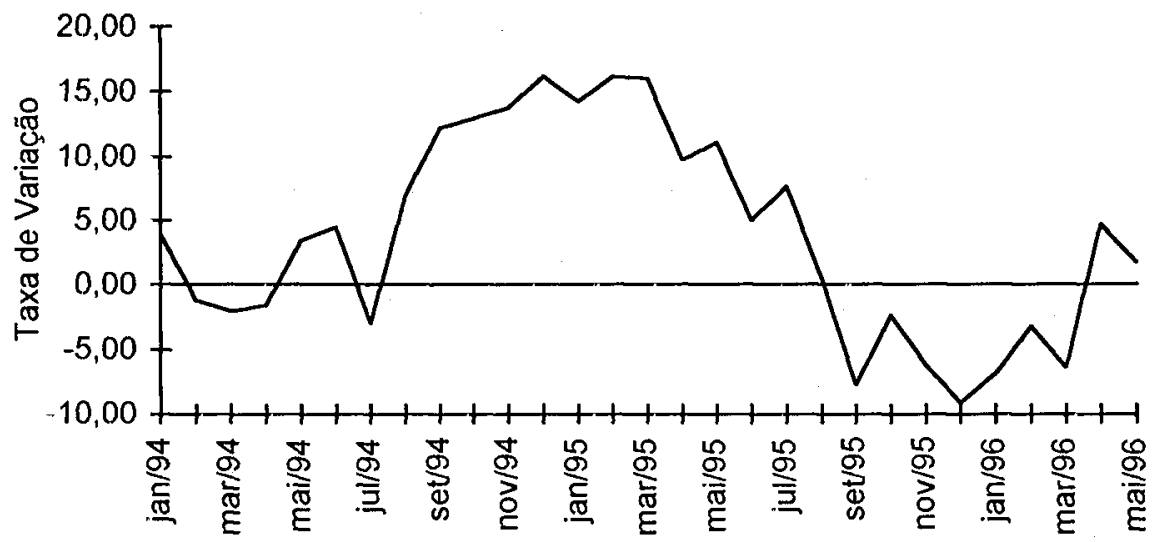

Fonte: FIERGS/Nücleo de Estatística.

Figura 6

Produção física da indústria do Rio Grande do Sul (variação em relação ao mesmo mês do ano anterior)

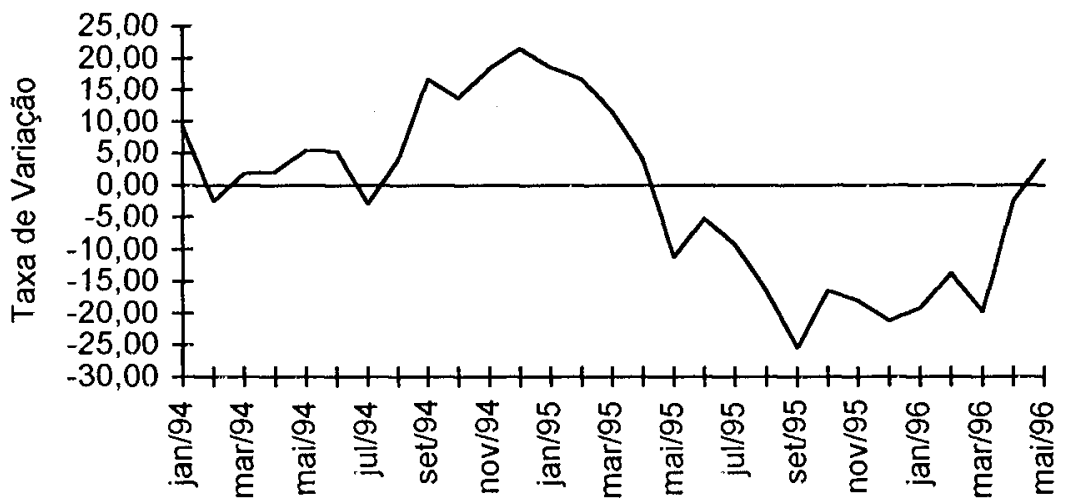

Fonte: IBGE/DPE/Departamento de Industria 
No caso do indice de produção física da indústria do IBGE para a indústria gaúcha, o comportamento é bastante semelhante ao do IDI. Contudo a magnitude das variações é substancialmente maior, vale dizer, tanto a fase de crescimento como a de desaceleração ficam amplificadas. O índice do IBGE atinge uma taxa mensal máxima de crescimento em relação ao mesmo mês do ano anterior em dezembro de $1994(21,55 \%)$ e, a partir de então, ao contrário da taxa de crescimento do IDI que fica estável até março de 1995, começa a se desacelerar fortemente até abril de 1995. A partir de então, a produção industrial, medida pelo IBGE, começa a apresentar uma taxa de variação crescentemente negativa até setembro de 1995, a partir de quando se estabiliza em torno de $-18 \%$ até março de 1996 . Os dados mais recentes para os meses de abril e maio mostram um início de recuperação, com a taxa de variação de, respectivamente, $-2,48 \%$ e $+3,80 \%$. Cabe destacar, contudo, que o resultado positivo do mês de maio está influenciado pela greve dos petroleiros que afetou a produção da indústria no mês de março de 1995, deprimindo assim a base de comparação para março de 1996.

Figura 7

Produção industrial gaúcha para setores selecionados

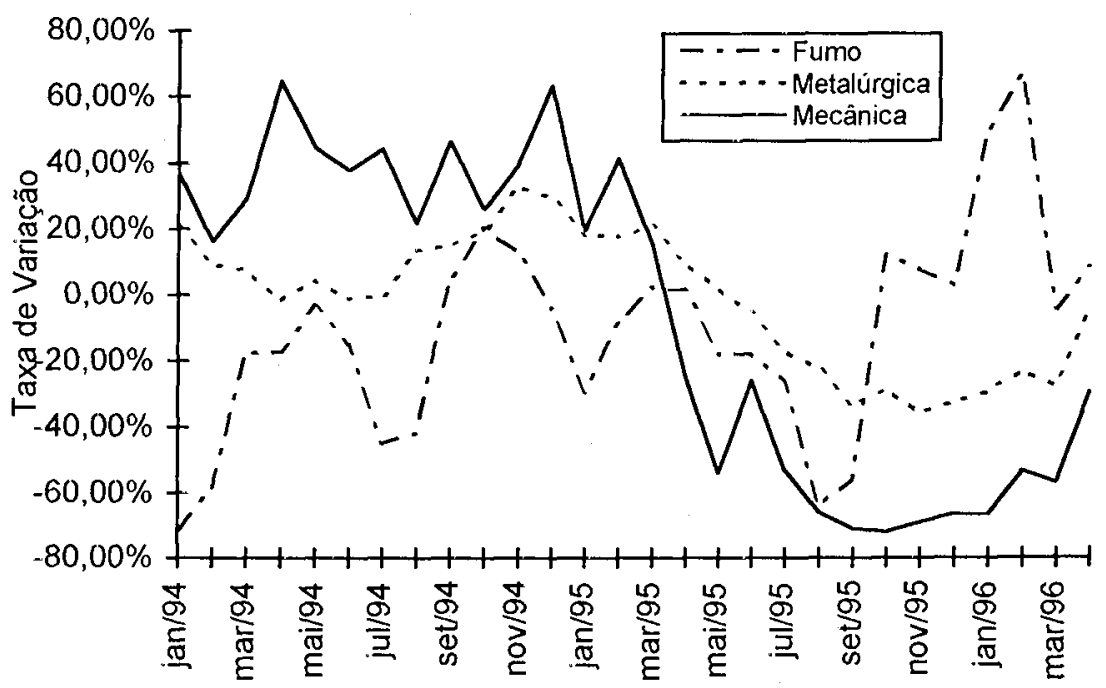

Fonte: IBGE/DPE/Departamento de Indústria 
Do ponto de vista da análise setorial da indústria gaúcha, vamos nos concentrar apenas nos seis principais setores, a saber, Produtos Alimentares, Química, Metalúrgica, Mecânica, Fumo e Calçados e Vestuário. Para as indústrias mecânica e metalúrgica existem duas fases distintas, uma de crescimento e outra de recessão, bem-delimitadas, embora a amplitude de variação da produção no setor mecânico tenha sido maior. Estes setores foram aqueles que ,ao mesmo tempo, apresentaram os maiores crescimentos de produção após o inicio do Plano Real e as maiores quedas a partir de março de 1995. A indústria mecânica foi particularmente atingida pela queda na produção agricola do Rio Grande do Sul que ocasionou uma redução na demanda por tratores, colheitadeiras e outras máquinas agricolas. No caso das indústrias de fumo e de vestuário e calçados é interessante notar que elas já vinham em uma fase recessiva mesmo antes do início do Plano Real e, neste sentido, o seu fraco desempenho não pode ser simplesmente creditado à política recessiva adotada no final de 1994. A indústria de fumo já começou a dar alguns sinais, embora ainda instáveis, de crescimento de produção a partir de outubro de 1995.

Os setores com melhor desempenho na indústria gaúcha são a Química e Produtos Alimentares. Após uma queda brusca da produção em maio de 1995 , em função da greve dos petroleiros, a indústria química voltou a apresentar taxas de crescimento positivas, embora menores que as observadas no segundo semestre de 1995. Já a indústria de Produtos Alimentares foi muito beneficiada pela redistribuição de renda promovida pela estabilização de preços, pois o aumento de renda real das camadas mais pobres da população implicou uma crescente demanda por alimentos.

Tabela 4. Produção de grãos do Brasil e do Rio Grande do Sul (em milhões de toneladas)

\begin{tabular}{|c|c|c|c|c|c|c|c|c|c|c|c|c|c|c|}
\hline Anos & \multicolumn{3}{|c|}{ Arroz } & \multicolumn{3}{|c|}{ Milho } & \multicolumn{3}{|c|}{ Soja } & \multicolumn{3}{|c|}{ Trigo 1} & \multicolumn{2}{|c|}{ Total } \\
\hline & Brasil & RGS & $\%$ & Brasil & RGS & $\%$ & Brasil & RGS & $\%$ & Brasil & RGS & $\%$ & Brasil & RGS \\
\hline 1993 & 10,142 & 4,965 & 49,0 & 30,065 & 4,605 & 15,3 & 22,694 & 6,067 & $26,7 \mid$ & 2,201 & 0,917 & 41,7 & 65,102 & 16,102 \\
\hline 1994 & 10,499 & 4,230 & 40,3 & 32,487 & 4,751 & 14,6 & 24,912 & 5,443 & 21,9 & 2,092 & 0,809 & 38,7 & 69,990 & 15,233 \\
\hline 1995 & 10,811 & 5,038 & 46,6 & $|33,635|$ & 5,936 & 17,7 & 25,581 & 5,847 & 22,9 & 1,516 & 0,336 & 22,2 & 71,543 & 17,157 \\
\hline 1996 & 9,516 & 6.545 & 68,8 & $\mid 31,014$ & 3,299 & 10,6 & 23,050 & 4,321 & 18,8 & 2,140 & 0,916 & 42,8 & 65,720 & 15,081 \\
\hline
\end{tabular}

A crise na economia gaúcha em 1995 foi magnificada pelo fraco desempenho do setor agrícola, o que afetou profundamente o nivel de atividade econômica, especialmente no interior do Estado. O total da produção de grãos (arroz, soja, milho e trigo) no Rio Grande do Sul sofreu uma queda de 5,40\% entre 1993 e 1994, passado de 16,1 para 15,2 milhões de toneladas. Neste 
mesmo período, a produção brasileira passou de 65,1 para 70,0 milhões de grãos, representando um aumento de $7,51 \%$. Em 1995 a produção de grãos gaúcha apresentou melhores resultados em 1995 com um crescimento de $12,6 \%$, atingindo 17,2 milhões de toneladas, acompanhando assim a tendência do resto do Brasil que acabou colhendo uma safra de 71,5 milhões de toneladas. Merece especial destaque a produção gaúcha de trigo que caiu $63,36 \%$ entre 1993 e 1995. Os dados disponiveis para 1996 para o Rio Grande do Sul e para o Brasil indicam, na melhor da hipóteses, um retorno da produção aos niveis de 1993. No caso do Rio Grande do Sul, a redução na produção em 1996 está associada não apenas aos problemas econômicos por que passou a agricultura gaúcha desde o inicio do Plano Real, mas também a uma forte seca ocorrida no final de 1995.

Figura 8

Produção industrial gaúcha para setores selecionados

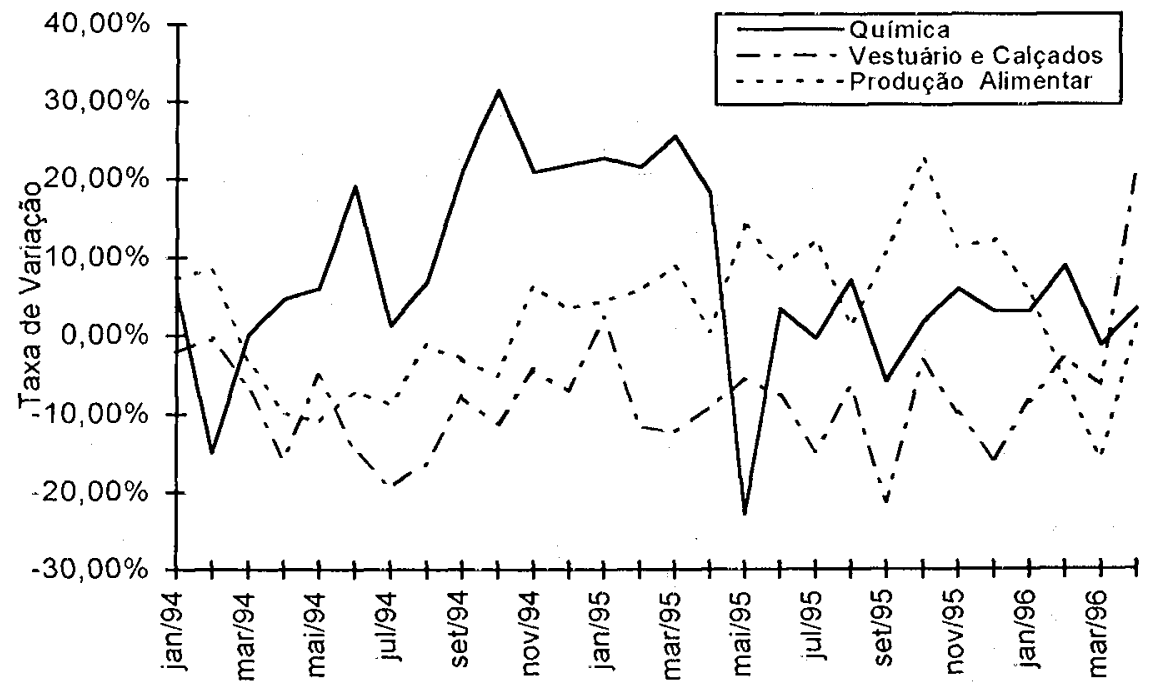

Fonte: IBGE/DPE/Departamento de Industria 
Figura 9

Relação entre os preços recebidos e preços pagos pelos agricultores gaúchos

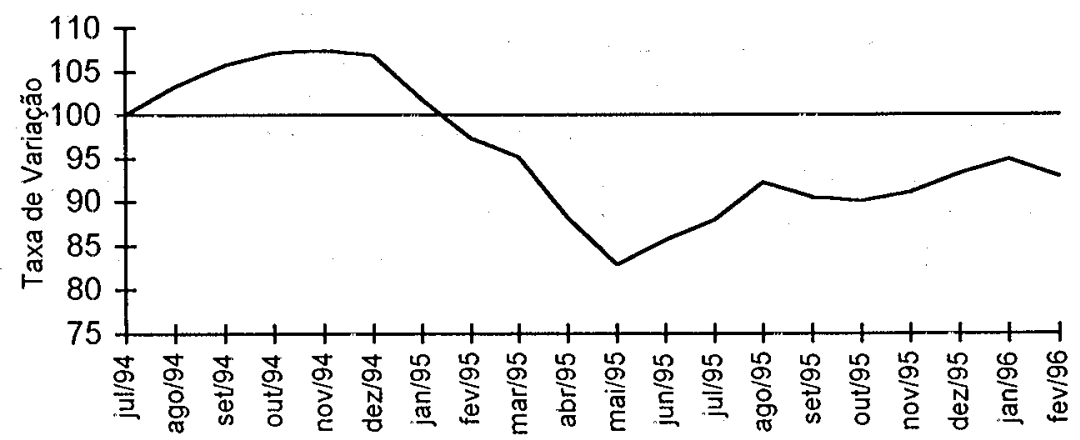

Fonte: Conjuntura Econômica

Tabela 5. Taxas de desemprego aberto (PME/IBGE) (médias anuais e trimestrais em \%)

\begin{tabular}{l|r|r|r}
\hline & Porto Alegre & São Paulo & Brasil $^{1}$ \\
\hline Média de 1991 & 4,27 & 5,51 & 4,81 \\
Média de 1992 & 5,57 & 6,60 & 5,89 \\
Média de 1993 & 4,02 & 5,67 & 5,28 \\
Média de 1994 & 4,06 & 5,35 & 4,97 \\
Média de 1995/1 & 3,70 & 4,69 & 4,34 \\
Média de 1995/2 & 4,76 & 5,04 & 4,64 \\
Média de 1995/3 & 5,20 & 5,85 & 5,08 \\
Média de 1995/4 & 4,91 & 5,53 & 4,82 \\
Média de 1996/1 & 6,45 & 7,26 & 6,06 \\
Média de 1996/2 & 6,27 & 6,82 & 5,81 \\
\hline
\end{tabular}

Notas: ${ }^{1}$ Total das regiões metropolitanas.

${ }^{2}$ Média de abril e maio.

Fonte: IPEA (1996).

Contudo o principal problema da agricultura gaúcha não está no lado da produção, mas sim no lado dos preços e do financiamento. A relação entre os preços recebidos e os preços pagos pelo agricultor gaúcho, que serve como aproximação da lucratividade do setor agricola, se deteriorou significativamente durante o Plano Real. A Figura 9 mostra que após um pequeno aumento entre 
setembro e novembro esta relação caiu rapidamente até março de 1995 , quando atingiu um valor 17,14\% inferior àquele vigente em julho de 1994 . Apesar da recuperação observada a partir de então, a relação entre os preços recebidos e os preços pagos pelo agricultor gaúcho em fevereiro de 1996 ainda apresenta uma queda de $7,11 \%$ em relação a julho de 1994 . A maior redução de preços reais ocorreu para a soja, seguida do milho e do arroz, tendo sido o trigo o produto que apresentou menor redução real de preços até o primeiro trimestre de 1995.

Como resultado da crise na agricultura e na indústria, O PIB do Rio Grande do Sul apresentou taxas de crescimento inferiores ao PIB do Brasil nos anos de 1994 e 1995. Enquanto o PIB brasileiro apresentou um crescimento de, respectivamente, $5,6 \%$ e $4,2 \%$, o PIB gaúcho cresceu apenas $2,7 \%$ e $-0,2 \%$, reduzindo assim a participação do PIB do Rio Grande do Sul no PIB nacional. $\mathrm{Na}$ verdade, nas últimas décadas tem havido uma quase constante perda de participação do Rio Grande do Sul no PIB brasileiro. Esta participação, que já foi de $8,6 \%$ em 1970 está atualmente reduzida para algo em torno de 7,4\%. Entre os elementos importantes na explicação desta perda de dinamismo da economia gaúcha estão, sem dúvida, a crônica deficiência de infra-estrutura e o descontrole das finança públicas estaduais, que acabam por reduzir a capacidade de atração de investimentos para o Estado. ${ }^{7}$

Tabela 6. Salário minimo e renda média (em reais de dez/1995)

\begin{tabular}{l|r|r|r|r}
\hline & Salário minimo & \multicolumn{3}{|c}{ Rendimento real médio } \\
\cline { 3 - 5 } & Real & Porto Alegre & São Paulo & Brasil $^{1}$ \\
\hline Média de 1991 & 80,34 & 436,76 & 599,59 & 496,26 \\
Média de 1992 & 86,31 & 354,45 & 497,99 & 412,99 \\
Média de 1993 & 94,57 & 391,91 & 561,91 & 458,24 \\
Média de 1994 & 88,60 & 434,72 & 622,23 & 484,48 \\
Média de 1995/1 & 83,15 & 490,09 & 645,28 & 505,08 \\
Média de 1995/2 & 100,43 & 522,55 & 660,62 & 528,87 \\
Média de 1995/3 & 105,83 & 526,96 & 664,42 & 535,60 \\
Média de 1995/4 & 101,60 & 527,61 & 695,35 & 564,02 \\
Média de 1996/1 & 97,28 & 513,60 & 676,74 & 548,01 \\
Média de 1996/2 & 102,62 & 508,87 & 661,46 & 549,91 \\
\hline
\end{tabular}

Notas: (1) Total das regiōes metropolitanas

Fonte: IPEA (1996)

\footnotetext{
7 Para maiores detalhes sobre a participação do Rio Grande do Sul no PIB brasileiro ver Azevedo, Monteiro e Portugal (1996) e Silva e outros (1996).
} 
Como resultado desta contração no nivel de atividade ocorrida em 1995, a taxa de desemprego aberto, medida pela PME/IBGE, na Região Metropolitana de Porto Alegre ficou, pela primeira vez nos anos noventa, acima da média nacional a partir do segundo trimestre de 1995.

Por outro lado, a manutenção de taxas reduzidas de inflação permitiu um aumento tanto no salário mínimo real, como nos rendimentos reais dos trabalhadores. Após uma queda real de 6,31\% entre 1993 e 1994, o salário mínimo real voltou a aumentar em 1995 , ficando $3,37 \%$ acima do valor vigente em 1993. Os dados para os primeiro e segundo trimestres de 1996 confirmam esta tendência, apresentando aumentos em termos reais de $17,0 \%$ e $2,2 \%$ em relação ao mesmo período de 1995 . Se, de um lado, a Região Metropolitana de Porto Alegre vem experimentando uma taxa de desemprego acima da nacional, por outro lado, sua renda média real vem crescendo acima da média nacional para o período posterior ao Plano Real. A renda média real na região metropolitana de Porto Alegre aumentou 10,92\% em 1994 e 18,88\% em 1995, enquanto que no Brasil como um todo o aumento foi de, respectivamente, $5,73 \%$ e $10,10 \%$. O ganho de renda real de Porto Alegre foi também superior àquele observado em São Paulo, onde a renda média real aumentou 10,73\% em 1994 e $7,10 \%$ em $1995 .^{\circ}$ Esta tendência não se manteve nos dois primeiros trimestres de 1996, quando a renda média real em Porto Alegre subiu, respectivamente, $4,80 \%$ e $-2,62 \%$ em relação ao mesmo período do ano anterior, enquanto para o total das regiões metropolitanas do Brasil os aumentos foram de $8,50 \%$ e $3,98 \%$.

\section{AS DIFICULDADES FINANCEIRAS DO ESTADO}

Na medida em que são o governo e o setor financeiro os principais parceiros da inflação, não surpreende que sejam exatamente estes setores que estejam passando por maiores dificuldades com a estabilização dos preços. 0 crescimento econômico acelerado observado após julho de 1994 provocou um aumento significativo da arrecadação fazendo com que a carga tributária bruta chegasse a $30,5 \%$ do PIB em 1995. Contudo a maioria dos governos estaduais, e em parte o próprio Governo Federal, não se deram conta que, por outro lado, - fim da inflação significava também o fim da demagogia dos aumentos nominais de salário. No Rio Grande do Sul, tanto o Governo Colares, em 1994, quanto o Governo Britto, em 1995, concederam substanciais aumentos nominais de salário que, com baixa inflação, representaram significativo

\footnotetext{
${ }^{8}$ Na verdade, o aumento da renda real em 1994 e 1995 na região metropolitana de Porto Alegre foi o maior entre todas as demais regiões metropolitanas pesquisadas pelo IBGE (São Paulo, Belo Horizonte, Rio de Janeiro Recife e Salvador)
} 
comprometimento da receita própria liquida com o pagamento de salários e encargos.

A miopia do atual governo gaúcho chegou a tal ponto que em maio de 1995, quando as despesas com pessoal já chegavam a quase $77 \%$ da receita própria líquida, foi enviado a Assembléia Legislativa uma proposta de lei salarial, a entrar em vigor a partir de abril de 1996, que contemplava reajustes semestrais, gatilho salarial e aumentos reais. Como mostra a Figura 10 após o inicio do Plano Real, em função do crescimento acelerado da economia, a arrecadação real do ICMS gaúcho também cresceu substancialmente. Os dados para dezembro de 1995 e janeiro de 1996 estão distorcidos em decorrência de uma antecipação de recolhimento de ICMS, que fez crescer demasiadamente a arrecadação de dezembro e, conseqüentemente, reduziu a de janeiro. Fica claro que, entre agosto de 1994 e julho de 1995, houve um crescimento na arrecadação mensal do ICMS gaúcho, quando comparamos com o mesmo período do ano anterior. A partir de agosto de 1995, contudo, a recessão levou a um processo de redução na arrecadação real de ICMS.

Figura 10

Arrecadação real do ICMS

(variação em relação ao mesmo mês do ano anterior)

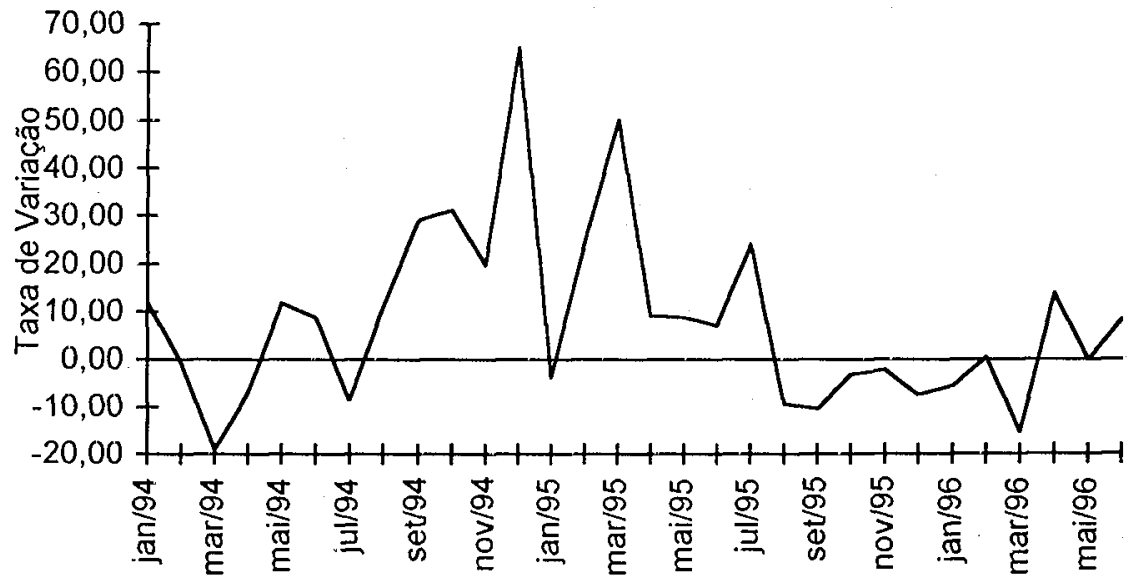

Fonte: Secretaria de Fazenda - RS

Frente à necessidade premente de equilibrar as contas públicas e a lentidão do Congresso em aprovar a Reforma Administrativa, o Governa do Rio Grande do Sul iniciou uma série de ações visando a reduzir os gastos públicos. Destacam-se o programa de demissão voluntária e a imposição de um teto 
salarial de $R \$ 6000,00$ para os salários de funcionários dos poderes executivo, legislativo e judiciário. A Lei do Teto Salarial, que pouparia aos cofres públicos R\$ 12 milhões por mês em uma folha salarial mensal de R\$ 273 milhões, foi aprovada pela Assembléia Legislativa, mas teve seus efeitos suspensos por iniciativa do poder judiciário gaúcho. Já o plano de demissão voluntária, embora tenha conseguido reduzir o número total de funcionários públicos, muitas vezes - faz de forma desbalanceada, não conseguindo cortar pessoal naqueles setores onde há excesso de quadros.

Como pode ser visto pelos dados da Tabela 7, em 1993 e 1994 o Estado do Rio Grande do Sul gastou cerca de $67 \%$ de sua receita própria líquida com o pagamento da folha de pessoal e encargos, mas já em 1995, em função da estabilização de preços e dos aumentos concedidos no ano anterior, a relação entre as despesas de pessoal e a receita própria líquida já atingia $82 \%$. Os dados para 1996 não indicam uma mudança substancial, pois apenas para o primeiro semestre esta relação já atingiu $78 \%$, um percentual ligeiramente superior ao registrado no primeiro semestre de 1995. Na medida em que a receita própria liquida fica crescentemente comprometida com os gastos em pessoal, sobram cada vez menos recursos para gastos em investimento. Enquanto que em 1993 e 1994 para cada real gasto com pagamento de pessoal 0,16 centavos eram investidos, em 1995 foram gastos apenas 0,12 centavos em investimento para cada real usados para o pagamento da folha de salários.

Tabela 7. Relações entre os gastos

com pessoal, investimento e a receita própria liquida (RPL)

\begin{tabular}{l|r|r|r}
\hline Ano & Pessoal/R.P.L. (\%) & Inv./R.P.L. (\%) & Inv./Pessoal \\
\hline 1993 & 67,81 & 10,37 & 0,150 \\
1994 & 68,96 & 11,92 & 0,170 \\
1995 & 82,26 & 10,26 & 0,120 \\
$1996^{1}$ & 78,59 & 6,16 & 0,079 \\
\hline
\end{tabular}

Notas: ${ }^{1}$ Dados referentes ao primeiro semestre.

Fonte: Elaboração própria, a partir de dados primários da Secretaria da Fazenda do RGS 
Figura 11

Gastos com a folha de pessoal no Rio Grande do Sul

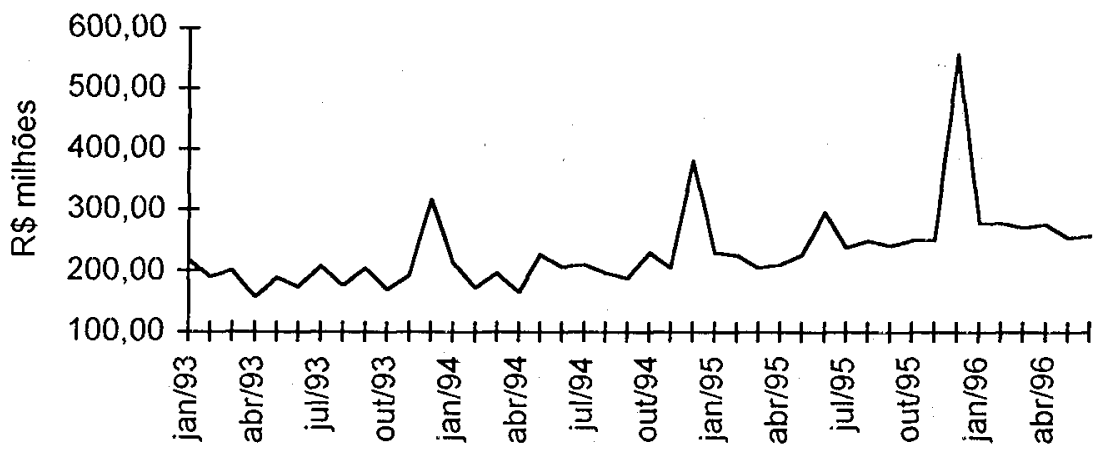

Fonte: Secretaria de Fazenda - RS

Apesar do erro inicial quanto a política salarial para o funcionalismo público estadual, o governo gaúcho iniciou vários programas que devem ter um efeito positivo sobre o Estado a médio e longo prazo. Destacam-se os contratos de gestão com as companhias estaduais de telefonia (CRT) e de energia elétrica (CEEE) e o programa de qualidacie no setor público.

\section{CONCLUSÃO}

Os resultados mais recentes disponiveis para a indústria brasileira e gaúcha mostram alguns indícios de estabilidade e mesmo de recuperação da produção, parecendo demostrar que o pior da crise já passou. Uma recente pesquisa do SEBRAE-RS realizada no Rio Grande do $\mathrm{Sul}^{9}{ }^{9}$ por exemplo, mostra que não apenas o volume de vendas aumentou, como também a grande maioria dos empresários consultados esperam ampliar sua produção no terceiro trimestre deste ano. As perspectivas de retomada gradual para o segundo semestre parecem indicar que, no que diz respeito ao nivel de atividade, o ano de 1996 deverá ser a imagem invertida de 1995.

Os principais desajustes macroeconômicos da economia brasileira encontram-se no déficit público e no setor externo. Do ponto de vista do balanço de pagamentos seria desejável que o governo mantivesse a politica de deslizamento gradual da banda cambial, avaliando sempre a possibilidade, de

${ }^{9}$ Ver SEBRAE-RS (1996) 
acordo com o desempenho da inflação, de acelerar as desvalorizações nominais da taxa de câmbio como forma de recuperar o atraso cambial existente. Por outro lado, o ajuste do setor público vai depender da capacidade do Governo Federal e do Congresso em promover ampla desvinculação do gasto público e reforma administrativa adequada.

Por fim, fica também clara a inexistência de uma política agrícola de longo prazo clara, que fixe metas quantitativas a serem atingidas e estabeleça, concomitantemente, parâmetros estáveis de financiamento e preços mínimos. Isso faz com que a questão agrícola seja tratada de forma casuística, tentandose sempre reparar danos já causados.

\section{BIBLIOGRAFIA}

ARIDA, Pérsio e RESENDE, André Lara. Inflação inercial e reforma monetária: Brasil. In: ARIDA, P (org.), Inflação Zero: Brasil, Argentina e Israel Paz e Terra: Rio de Janeiro, 1996.

AZEVEDO, A. F. Z, MONTEIRO, S. M. e PORTUGAL, M. S. Estagnação econômica, descontrole dos gastos públicos e deficiência de infra-estrutura: o caso do Rio Grande do Sul. Indicadores Econômicos FEE, v 24, n. 3, p 97-130, 1996

GIAVAZZI, F. e PAGANO, M. The advantage of tying one's hands. European Economic Review, v. 32, p. $1055-1082,1988$

IPEA. Mercado de trabalho: análise e conjuntura Rio de Janeiro: DIPES/IPEA, n. 1, jun. 1996.

LOPES, F. L. P. Inflação inercial, hiperinflação e desinflação: notas e conjecturas. In: F.L. P. LOPES, Francisco L. O choque heterodoxo. Rio de Janeiro: Campus, 1986

MORAES, Roberto $C$. Os custos reais da inflação. Porto Alegre: Curso de Pós-Graduação em Economia, UFRGS, 1995. (Texto para Discussão n. 95/05, 22 p.).

PORTUGAL, Marcelo S. (org.) A economia do real uma análise da política econômica de estabilização, 1994-1996, Porto Alegre: Ortiz, 1996.

SARGENT, T. J. e WALLACE, N. Some Unpleasant Monetarist Arithmetic In: SARGENT, T. J. Rational expectations and inflation. Nova York: Harper \& Row Publishers, 1986.

SEBRAE-RS. Sondagem da atual conjuntura econômica e perspectivas para o segundo semestre de 1996. Porto Alegre: SEBRAE-RS, jun. 1996. 12 p.

SILVA, A B O et al. Produto Interno Bruto por Unidade da Federação Brasília: IPEA, Textos para Discussão n. 424, maio, 1996. 105 p.

\section{ABSTRACT \\ EFFECTS OF THE "PLANO REAL" ON THE RIO GRANDE DO SUL'S ECONOMY: EXPORTS, OUTPUT AND PUBL.IC FINANCE IN THE FIRST TWO YEARS OF THE "REAL"}

The main idea of this paper is to analyse the impacts of the economic policy implemented in the first two years of the Plano Real on the economy of Rio Grande do Sul. We shall concentrate on the effects of Plano Real on three basic aspects of Rio Grande do Sul's economy: exports, output and public finance. The prices stabilisation effort, that was mainly based on the valorisation of the real exchange rate and on the reduction of agriculture prices, punished severely state of Rio Grande do Sul, which economy relies mainly on agriculture products and exports. On the other hand, the reduction of inflation rate was responsible for the increase on the state public deficit, due to high weight of the pay roll on the state budget.

Key Words: Rio Grande do Sul; Stabilisation Policy; Regional Economics. 


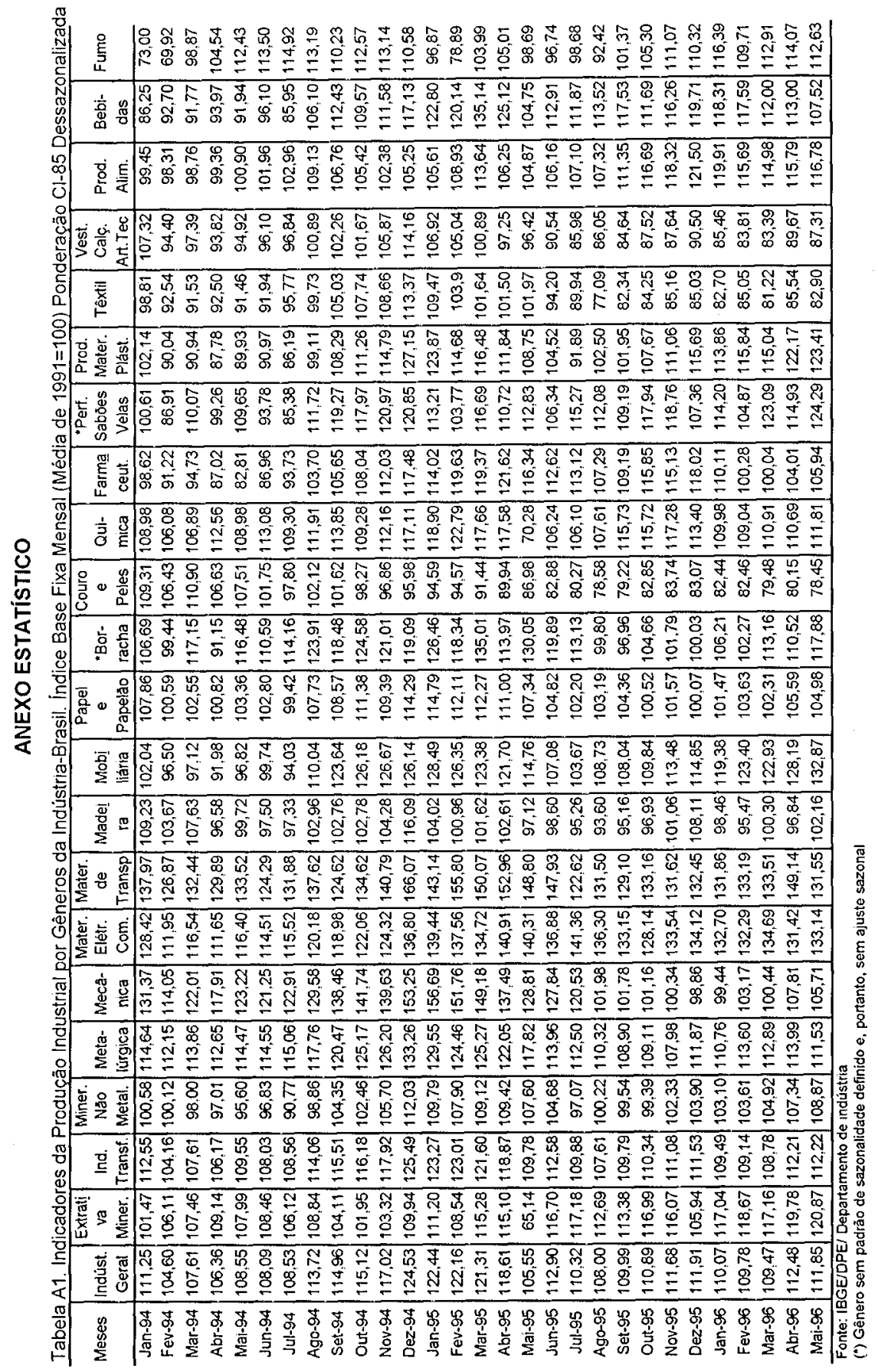




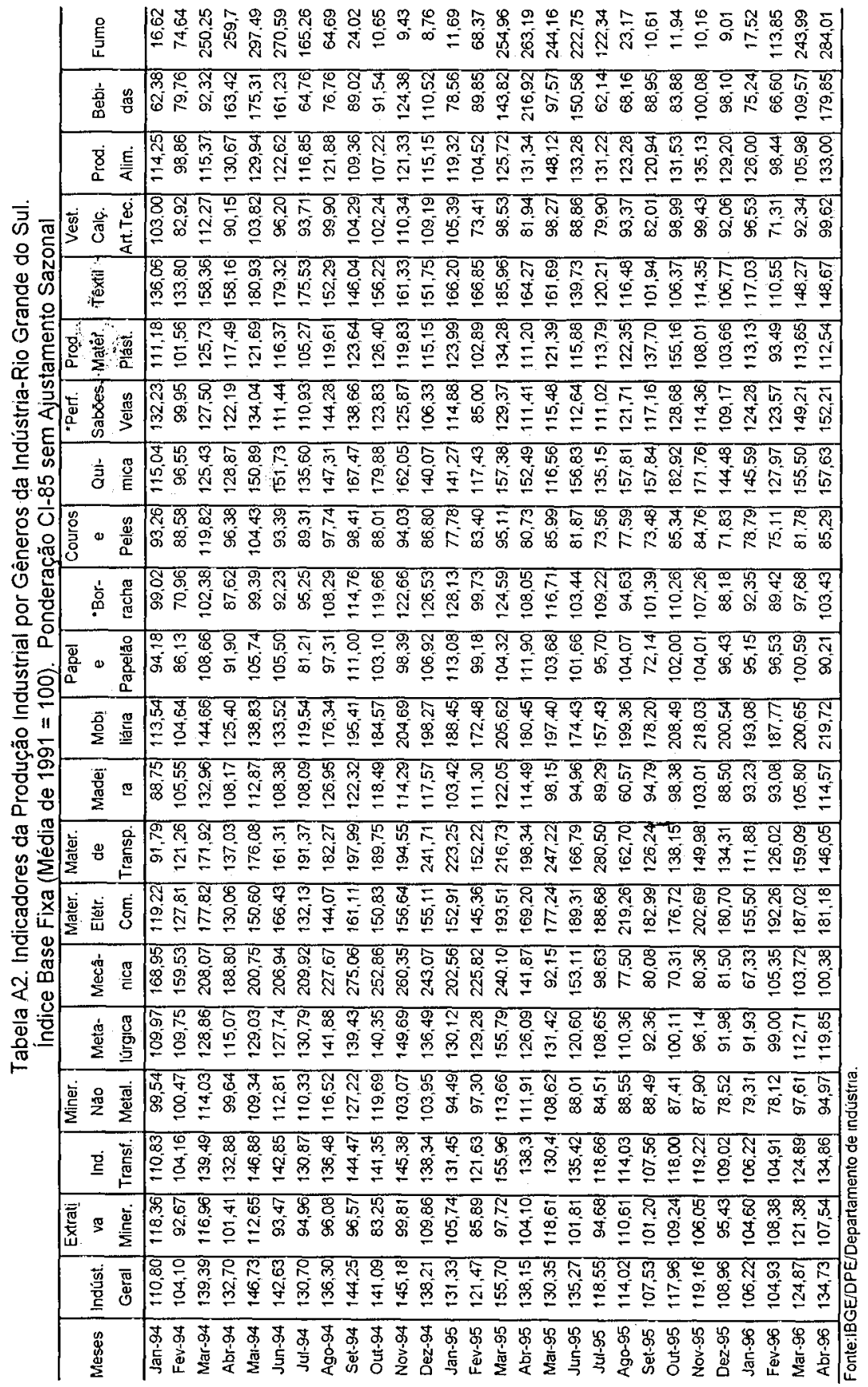


Tabela A3. Exportações do Rio Grande do Sul (US\$ milhões)

\begin{tabular}{|c|c|c|c|c|c|c|}
\hline & Valor & $\begin{array}{c}\text { Variação } \\
\text { Mensal }\end{array}$ & $\begin{array}{l}\text { Variação em } \\
\text { rel, ao mesmo } \\
\text { mês do ano ant, }\end{array}$ & $\begin{array}{c}\text { Valor } \\
\text { acumulado } \\
\text { em } 12 \text { meses }\end{array}$ & $\begin{array}{c}\text { Taxa de } \\
\text { crescimento acum, } \\
\text { em } 12 \text { meses }\end{array}$ & $\begin{array}{c}\text { Valor } \\
\text { acurnulado } \\
\text { no ano }\end{array}$ \\
\hline $\mathrm{jan} / 94$ & 356 & $.15,76$ & 1,46 & 5217 & 18,19 & 356 \\
\hline fev/94 & 300 & $-15,73$ & $-36,95$ & 5042 & 4,43 & 656 \\
\hline $\mathrm{mar} / 94$ & 325 & 8,33 & $-21,99$ & 4950 & $-1,79$ & 981 \\
\hline$a b r / 94$ & 428 & 31,69 & 2,00 & 4958 & $-6,35$ & 1409 \\
\hline mai/94 & 522 & 21,96 & 16,08 & 5031 & $-9,00$ & 1931 \\
\hline jun/94 & 493 & $-5,56$ & $-10,94$ & 4970 & $-12,06$ & 2424 \\
\hline jul/94 & 466 & $-5,48$ & $.3,19$ & 4955 & $-13,57$ & 2890 \\
\hline ago/94 & 515 & 10,52 & 3,06 & 4970 & $-16,63$ & 3405 \\
\hline set/94 & 470 & $-8,74$ & 7,43 & 5003 & $-15,77$ & 3875 \\
\hline out/94 & 400 & $-14,89$ & 7,79 & 5032 & $-13,31$ & 4275 \\
\hline nov/94 & 365 & $-8,75$ & 8,93 & 5061 & $-6,26$ & 4640 \\
\hline $\operatorname{dez} / 94$ & 388 & 6,30 & $-8,11$ & 5028 & $-3,55$ & 5028 \\
\hline jan/95 & 358 & $-7,73$ & 0,56 & 5030 & $-3,58$ & 358 \\
\hline fev/95 & 356 & $-0,56$ & 18,67 & 5086 & 0,87 & 714 \\
\hline mar/95 & 332 & $-6,74$ & 2,15 & 5093 & 2,89 & 1046 \\
\hline$a b r / 95$ & 371 & 11,75 & $-13,32$ & 5036 & 1,57 & 1417 \\
\hline mai/95 & 524 & 41,24 & 0,38 & 5038 & 0,14 & 1941 \\
\hline jun/95 & 536 & 2,29 & 8,72 & 5081 & 2,23 & 2477 \\
\hline jul/95 & 492 & $-8,21$ & 5,58 & 5107 & 3,07 & 2969 \\
\hline ago/95 & 532 & 8,13 & 3,30 & 5124 & 3,10 & 3501 \\
\hline set/95 & 433 & $-18,61$ & $-7,87$ & 5087 & 1,68 & 3934 \\
\hline out/95 & 416 & $-3,93$ & 4,00 & 5103 & 1,41 & 4350 \\
\hline nov/95 & 445 & 6,97 & 21,92 & 5183 & 2,41 & 4795 \\
\hline dez/95 & 386 & $-13,26$ & $-0,52$ & 5181 & 3,04 & 5181 \\
\hline jan/96 & 355 & $-8,03$ & $-0,84$ & 5178 & 2,94 & 355. \\
\hline $\mathrm{fev} / 96$ & 412 & 16,06 & 15,73 & 5234 & 2,91 & 767 \\
\hline mar/96 & 385 & $-6,55$ & 15,96 & 5287 & 3,81 & 1152 \\
\hline $\mathrm{abr} / 96$ & 464 & 20,52 & 25,07 & 5380 & 6,83 & 1616 \\
\hline mai/96 & 602 & 29,74 & 14,89 & 5458 & 8,34 & 2218 \\
\hline jun/96 & 535 & $-11,08$ & $-0,10$ & 5458 & 7,42 & 2754 \\
\hline
\end{tabular}

Fonte: DPPC/SECEX 
Tabela A4. Índice de Desempenho Industrial - IDI/RS

\begin{tabular}{|c|c|c|c|c|c|}
\hline Período & $\begin{array}{c}\text { Indice B,F, } \\
92=100 \\
\end{array}$ & $\begin{array}{c}\text { Variação } \\
\text { Mensal }\end{array}$ & $\begin{array}{l}\text { Variação } \\
12 \text { meses } \\
\end{array}$ & $\begin{array}{c}\text { Mesmo mês ano } \\
\text { anterior }\end{array}$ & $\begin{array}{c}\text { Acumulado } \\
\text { no ano }\end{array}$ \\
\hline $\operatorname{jan} / 94$ & 102,65 & $-2,89$ & 7,20 & 4,00 & 4,00 \\
\hline fev/94 & 96,38 & $-6,09$ & 6,62 & $-1,16$ & 1,44 \\
\hline $\mathrm{mar} / 94$ & 110,22 & 14,34 & 5,30 & $-2,11$ & 0,14 \\
\hline$a b r / 94$ & 106,54 & $-3,33$ & 4,76 & $-1,58$ & $-0,30$ \\
\hline $\mathrm{mai} / 94$ & 113,74 & 6,76 & 4,57 & 3,50 & 0,49 \\
\hline jun/94 & 114,72 & 0,86 & 4,30 & 4,46 & 1,17 \\
\hline jul/94 & 107,56 & $-6,23$ & 3,42 & $-2,99$ & 0,56 \\
\hline ago/94 & 118,19 & 9,88 & 3,28 & 6,99 & 1,39 \\
\hline set/94 & 121,38 & 2,70 & 3,83 & 12,20 & 2,60 \\
\hline out/94 & 121,14 & $-0,19$ & 4,33 & 12,90 & 3,63 \\
\hline nov/94 & 125,10 & 3,27 & 4,66 & 13,82 & 4,57 \\
\hline $\operatorname{dez} / 94$ & 122,80 & $-1,85$ & 5,52 & 16,17 & 5,52 \\
\hline $\mathrm{jan} / 95$ & 117,30 & $-4,48$ & 6,33 & 14,27 & 14,27 \\
\hline fev/95 & 112,00 & $-4,51$ & 7,64 & 16,19 & 15,20 \\
\hline $\mathrm{mar} / 95$ & 127,94 & 14,23 & 9,21 & 16,07 & 15,51 \\
\hline$a b r / 95$ & 116,88 & $-8,64$ & 10,15 & 9,70 & 14,02 \\
\hline mai/95 & 126,41 & 8,16 & 10,81 & 11,14 & 13,40 \\
\hline jun/95 & 120,42 & $-4,74$ & 10,83 & 4,97 & 11,90 \\
\hline jul/95 & 115,86 & $-3,79$ & 11,75 & 7,71 & 11,30 \\
\hline ago/95 & 118,66 & 2,42 & 11,13 & 0,40 & 9,82 \\
\hline set/95 & 112,03 & $-5,59$ & 9,30 & $-7,70$ & 7,68 \\
\hline out/95 & 118,29 & 5,58 & 7,95 & $-2,36$ & 6,58 \\
\hline nov/95 & 117,38 & $-0,76$ & 6,15 & $-6,17$ & 5,29 \\
\hline $\operatorname{dez} / 95$ & 111,64 & $-4,89$ & 4,00 & $-9,08$ & 4,00 \\
\hline jan/96 & 109,24 & $-2,15$ & 2,30 & $-6,87$ & $-6,87$ \\
\hline $\mathrm{fev} / 96$ & 108,41 & $-0,76$ & 0,90 & $-3,21$ & $-5,08$ \\
\hline $\mathrm{mar} / 96$ & 119,77 & 10,48 & $-0,95$ & $-6,38$ & $-5,55$ \\
\hline$a b r / 96$ & 122,44 & 2,23 & $-1,28$ & 4,76 & $-3,01$ \\
\hline mai/96 & 128,59 & 5,02 & $-2,00$ & 1,73 & $-2,01$ \\
\hline
\end{tabular}

Fonte: FIERGS/Núcleo de Estatística 
Tabela A5. Relações entre os gastos com Pessoal, Investimento e a Receita Própria Liquida (RPL)

\begin{tabular}{l|r|r|r}
\hline Trimestre & Pessoal/R.P.L. $(\%)$ & Inv, R.P.L (\%) & \multicolumn{1}{|c}{ Inv./Pessoal } \\
\hline $1993 / 1$ & 78,38 & 9,23 & 0,12 \\
$1993 / 2$ & 63,40 & 8,21 & 0,13 \\
$1993 / 3$ & 67,72 & 12,07 & 0,18 \\
$1993 / 4$ & 61,74 & 11,94 & 0,19 \\
$1994 / 1$ & 71,93 & 12,00 & 0,17 \\
$1994 / 2$ & 60,78 & 7,21 & 0,12 \\
$1994 / 3$ & 66,78 & 8,87 & 0,13 \\
$1994 / 4$ & 76,34 & 19,60 & 0,26 \\
$1995 / 1$ & 74,58 & 2,52 & 0,03 \\
$1995 / 2$ & 78,66 & 5,00 & 0,06 \\
$1995 / 3$ & 80,79 & 10,02 & 0,12 \\
$1995 / 4$ & 95,03 & 23,51 & 0,25 \\
$1996 / 1$ & 79,25 & 5,17 & 0,07 \\
$1996 / 2$ & 77,92 & 7,16 & 0,09 \\
\hline
\end{tabular}

Fonte: Secretaria da Fazenda do RGS, 